\title{
Ginsenosides from the fruits of Panax ginseng and their cytotoxic effects on human cancer cell lines
}

\author{
Jung Eun Gwag ${ }^{1}$ Yeong-Geun Lee ${ }^{1} \cdot J_{e o n}$ Hwang-Bo ${ }^{1} \cdot$ Hyoung-Geun Kim ${ }^{1}$. \\ Seon Min Oh ${ }^{1,2} \cdot$ Dae Young Lee ${ }^{2}$ (D) $\cdot$ Nam-In Baek ${ }^{1}$ (D)

\section{인삼(Panax ginseng) 열매로부터 분리한 ginsenoside의 동정 및 암세포독성 효과}

\author{
곽정은 ${ }^{1} \cdot$ 이영근 ${ }^{1} \cdot$ 황보전 $^{1} \cdot$ 김형근 $^{1} \cdot$ 오선민 ${ }^{1,2} \cdot$ 이대영 ${ }^{2} \cdot$ 백남인 $^{1}$
}

Received: 2 October 2018 / Accepted: 2 November 2018 / Published Online: 31 December 2018

(C) The Korean Society for Applied Biological Chemistry 2018

\begin{abstract}
The fruits of Panax ginseng were extracted with $80 \%$ aqueous $\mathrm{MeOH}$ and the concentrates were partitioned into EtOAc, $n$ - $\mathrm{BuOH}$, and $\mathrm{H}_{2} \mathrm{O}$ fractions. The repeated $\mathrm{SiO}_{2}$ and octadecyl $\mathrm{SiO}_{2}$ column chromatographies for the EtOAc fraction led to isolation of five ginsenosides. The chemical structures of these compounds were determined as ginsenoside F1 (1), ginsenoside F2 (2), ginsenoside F3 (3), ginsenoside Ia (4), notoginsenoside Fe (5) based on spectroscopic analyses including nuclear magnetic resonance, MS, and infrared. Compounds 2-5 were isolated for the first time from the fruits of $P$. ginseng in this study. All isolated compounds were evaluated for cytotoxic activities against human cancer cell lines such as HCT-116, SK-OV-3, human cervix adenocarcinoma (HeLa), HepG2, and SK-MEL-5. Among them compounds $\mathbf{2}, \mathbf{4}$, and $\mathbf{5}$ showed significant cytotoxicity on cancer
\end{abstract}

Nam-In Baek $(\bowtie)$

E-mail: nibaek@khu.ac.kr

Dae Young Lee $(\bowtie)$

E-mail: dylee0809@gmail.com

${ }^{1}$ Graduate School of Biotechnology and Department of Oriental Medicine Biotechnology, Kyung Hee University, Yongin 17104, Republic of Korea

${ }^{2}$ Department of Herbal Crop Research, National Institute of Horticultural and Herbal Science, RDA, Eumseong 27709, Republic of Korea

This is an Open Access article distributed under the terms of the Creative Commons Attribution Non-Commercial License (http://creativecommons. org/licenses/by-nc/3.0/) which permits unrestricted non-commercial use, distribution, and reproduction in any medium, provided the original work is properly cited. cells. Compound 2 exhibited cytotoxicity on SK-MEL-5, HepG2, and $\mathrm{HeLa}$ cells with $\mathrm{IC}_{50}$ values of $82.8,86.8$, and $78.3 \mu \mathrm{M}$, respectively. Compound 4 showed cytotoxicity on HCT-116, SKMEL-5, SK-OV-3, HepG2, and HeLa cells with $\mathrm{IC}_{50}$ values of $24.5,25.4,26.3,22.0$, and $24.9 \mu \mathrm{M}$, respectively. Compound 5 did on SK-MEL-5 cell with $\mathrm{IC}_{50}$ value of $81.7 \mu \mathrm{M}$. The cytotoxicity of ginsenoside 2, 4, and 5 isolated from the fruits of Panax ginseng showed strong inhibition effect against on cancer cells, all of which have a glucopyranosyl moiety on C-3.

Keywords Cytotoxicity - Fruit - Ginsenoside $\cdot$ Human cancer cells $\cdot$ Panax ginseng

\section{서 론}

우리나라의 인삼은 고려인삼 (Panax ginseng)이라 불리며, Gillis 의 연구[1]에 따르면 인삼은 두릅나무과 (Araliaceae)에 속하는 여러해살이 초본 식물이다. 인삼의 속명인 Panax는 모든 것을 뜻하는 'Pan'과 치료를 뜻하는 'Axos'로 이루어져있다. 속명으 로 알 수 있듯이 인삼은 뿌리가 주로 한방에서 이용되는 대표 적인 약용식물로 $\mathrm{Li}$ 와 $\mathrm{Li}$ 의 연구[2]에 따르면 예로부터 강장제, 피로회복제로 사용되었으며 항암, 항산화, Singh 등의 연구[3]에 서 면역 증진의 효능이 보고 되어있다. Choi의 연구[4]에서 인 삼은 주요성분인 ginsenoside를 비롯하여 다양한 종류의 이차대 사산물을 함유하고있다. 특히 인삼의 사포닌인 ginsenoside는 $\mathrm{Kim}$ 등의 연구[5]에서 항암, 항산화, 항고혈압, $\mathrm{Kim}$ 등의 연구 
[6]에서 항당뇨 등의 활성이 보고되었으며, Lee 등의 연구[7]에 서 현재까지 수십 여종 이상이 분리 및 보고되었다. 최근 Wang 등의[8] 인삼 열매 성분 함량 연구에 의하면, 인삼 열매가 뿌리 에 비해 사포닌 함량이 2배 이상 많은 것을 알 수 있다. 또한 Yahara 등의 연구[9]에 따르면 인삼 열매에는 뿌리에는 존재하 지 않는 ginsenoside가 함유되어 있다. Ginsenoside에는 주요 ginsenoside인 ginsenoside $\mathrm{Rb} 1, \mathrm{Rb} 2, \mathrm{Re}, \mathrm{Rg} 1$ 등과, 미량 ginsenoside인 ginsenoside F1, F2, compound $\mathrm{K}$ 등이 존재한 다. 그 중 미량 ginsenoside는 주요 ginsenoside 에 비해 흡수 율이 높고, Chae 등의 연구[10]에서 약리 활성이 좋다고 알려 져 있으며, ginsenoside F2는 Mai 등의 연구[11]에서 항암 활성 이 뛰어난 것으로 알려져 있다. 본 연구에서는 인삼 열매로부 터 미량 ginsenoside 를 분리 및 구조 동정 하고, 그들에 대한 항암 활성을 평가하고자 실험을 진행하였다.

\section{재료 및 방법}

\section{실험재료}

실험에서 사용한 인삼(P. ginseng)의 열매는 2013년 2월에 농촌 진흥청에서 제공받아 실험을 진행하였으며, 표본시료(KNPCLHP-201302)는 경희대학교 생명과학대학 천연물화학실에 보관되 어 있다.

\section{시약 및 기기}

Column chromatography (c.c.)용 silica gel $\left(\mathrm{SiO}_{2}\right)$ resin은 Kiesel gel 60 (Merck, Darmstadt, Germany)을 octadecyl $\mathrm{SiO}_{2}$ (ODS)은 Lichroprep RP-18 (40-60 $\mu \mathrm{M}$, Merck)을 사용하 였다. Thin layer chromatography (TLC)는 Kiesel gel 60 F254와 RP-18 F254s (Merck)을 사용하였다. Nuclear magnetic resonance (NMR) 스펙트럼은 $400 \mathrm{MHz}$ FT-NMR spectrometer (Varian Inova AS-400, Palo Alto, CA, USA)를 사용하였고, infrared (IR) spectrum은 Perkin model 599B (Perkin-Elmer, Waltham, MA, USA)로 측정하였다. Fast atom bombardment mass spectrometry (FAB/MS)는 JEOL JMS-700 (Tokyo, Japan) 을 사용하여 측정하였다. UV lamp는 Spectroline (Model ENF-240 C/F, Spectronics Corporation, Westbury, NY, USA) 을 사용하였다. 세포독성 실험에서 사용한 배지 RPMI 1640와 Penicillin-Streptomycin은 GIBCOBRL, Life Technologies Inc. (Grand Island, NY, USA)에서 구입하였다. Fetal bovine serum (FBS)은 Hyclone (Logan, UT, USA) 제품을 사용하였고, 3[4,5-dimethylthiazol-2-yl]-2,5-diphenyltetrazolium bromide (MTT) 와 dimethyl sulfoxide (DMSO)는 Sigma ( $\mathrm{St}$, Louis, MO, USA)에서 구입하였다.

\section{추출 및 분리}

건조한 인삼의 열매 $6.3 \mathrm{~kg}$ 을 $80 \% \mathrm{MeOH}$ 수용액 $(30 \mathrm{~L})$ 으로 실 온에서 24 시간씩 3 회 반복 추출하였다. 얻어진 여액을 감압농 축하여 $1.4 \mathrm{~kg}$ 의 추출물을 얻었다. 얻어진 추출물은 $\mathrm{H}_{2} \mathrm{O}(3.0 \mathrm{~L})$ 와 ethyl acetate (EtOAc, $3.0 \mathrm{~L} \times 3), n$-butyl alcohol $(n-\mathrm{BuOH}$, $2.6 \mathrm{~L} \times 3)$ 로 분배 추출하였다. 각 층을 감압농축하여 $\mathrm{EtOAc}$ 분 획(PGE, $75.0 \mathrm{~g}), n-\mathrm{BuOH}$ 분획 $(\mathrm{PGB}, 470.0 \mathrm{~g})$ 및 $\mathrm{H}_{2} \mathrm{O}$ 분획
(PGH, $855.0 \mathrm{~g}$ )을 얻었다. $\mathrm{PGE}(75.0 \mathrm{~g})$ 에 대하여 $\mathrm{SiO}_{2}$ c.c. $(\phi$ $14.0 \times 16.0 \mathrm{~cm}, \mathrm{CHCl}_{3}-\mathrm{MeOH}=30: 1 \rightarrow \mathrm{CHCl}_{3}-\mathrm{MeOH}-\mathrm{H}_{2} \mathrm{O}=15: 3: 1$, 각 $60 \mathrm{~L}$ )를 실시하여, 총 24개의 분획(PGE-1-PGE-24)을 얻었다. 그 중에서 $\mathrm{PGE}-20$ 분획 $[1.6 \mathrm{~g}$, elution volume/total volume $(\mathrm{Ve} / \mathrm{Vt}) \quad 0.62-0.69]$ 에 대하여 $\mathrm{SiO}_{2}$ c.c. $\left(\phi 3.5 \times 12.0 \mathrm{~cm}, \mathrm{CHCl}_{3}-\right.$ $\mathrm{MeOH}-\mathrm{H}_{2} \mathrm{O}=13: 3: 1,3.0 \mathrm{~L}$ )를 실시하여, 총 16 개의 분획(PGE20-1-PGE-20-16)을 얻었다. 이 중 PGE-20-7 분획 $(86.4 \mathrm{mg}, \mathrm{Ve} /$ $\mathrm{Vt} 0.19-0.22)$ 에 대하여 ODS c.c. $\left(\phi 2.0 \times 7.0 \mathrm{~cm}, \mathrm{MeOH}-\mathrm{H}_{2} \mathrm{O}=\right.$ $2: 1,300 \mathrm{~mL}$ )를 실시하여, 총 9개의 분획(PGE-20-7-1-PGE-207-9)을 얻었고, 화합물 1 (PGE-20-7-7, $59.6 \mathrm{mg}, \mathrm{Ve} / \mathrm{Vt} 0.33$ 0.61 , ODS TLC $\mathrm{R}_{\mathrm{f}} 0.5, \mathrm{MeOH}-\mathrm{H}_{2} \mathrm{O}=7: 2$ )을 분리하였다. PGE$20-11$ 분획(835.5 mg, $\mathrm{Ve} / \mathrm{Vt} \quad 0.48-0.69)$ 에 대하여 ODS c.c. $(\phi$ $4.0 \times 9.0 \mathrm{~cm}, \mathrm{MeOH}-\mathrm{H}_{2} \mathrm{O}=3: 2 \rightarrow 4: 1$, 각 $2.5 \mathrm{~L}$ )를 실시하여, 총 18 개의 분획(PGE-20-11-1-PGE-20-11-18)을 얻었고, 화합물 2 (PGE-20-11-16, $49.8 \mathrm{mg}$, Ve/Vt 0.86-0.90, ODS TLC $\mathrm{R}_{\mathrm{f}}$ 0.4, $\left.\mathrm{MeOH}-\mathrm{H}_{2} \mathrm{O}=6: 1\right)$ 을 분리하였다. PGE-20-11-11 분획 $(84.0 \mathrm{mg}$, $\mathrm{Ve} / \mathrm{Vt} \quad 0.28-0.43)$ 에 대하여 ODS c.c. $(\phi 3.0 \times 5.0 \mathrm{~cm}$, acetone$\mathrm{H}_{2} \mathrm{O}=2: 3,450 \mathrm{~mL}$ )를 실시하여, 총 10 개의 분획(PGE-20-11-111-PGE-20-11-11-10)을 얻었다. PGE-20-11-11-4 분획(54.0 mg, $\mathrm{Ve} / \mathrm{Vt} \quad 0.34-0.48)$ 에 대하여 $\mathrm{SiO}_{2}$ c.c. $\left(\phi 1.5 \times 8.0 \mathrm{~cm}, \mathrm{CHCl}_{3}-\right.$ $\mathrm{MeOH}-\mathrm{H}_{2} \mathrm{O}=10: 3: 1,800 \mathrm{~mL}$ )를 실시하여, 총 4 개의 분획 (PGE-20-11-11-4-1-PGE-20-11-11-4-4)을 얻었고, 화합물 3 (PGE-20-11-11-4-2, $41.0 \mathrm{mg}, \mathrm{Ve} / \mathrm{Vt}$ 0.43-0.69, $\mathrm{SiO}_{2}$ TLC $\mathrm{R}_{\mathrm{f}}$ $0.5, \mathrm{CHCl}_{3}-\mathrm{MeOH}-\mathrm{H}_{2} \mathrm{O}=65: 35: 10$ )을 분리하였다. $\mathrm{PGE}-22$ 분획 $(985.0 \mathrm{mg}, \mathrm{Ve} / \mathrm{Vt} 0.80-0.89)$ 에 대하여 $\mathrm{SiO}_{2}$ c.c. $(\phi 3.0 \times 12.0 \mathrm{~cm}$, $\mathrm{CHCl}_{3}-\mathrm{MeOH}-\mathrm{H}_{2} \mathrm{O}=16: 3: 1,2.2 \mathrm{~L}$ )를 실시하여, 총 18 개의 분획 (PGE-22-1-PGE-22-18)을 얻었다. PGE-22-16 분획 (205.5 mg, $\mathrm{Ve} / \mathrm{Vt} \quad 0.59-0.63)$ 에 대하여 ODS c.c. $(\phi 3.0 \times 9.0 \mathrm{~cm}, \mathrm{MeOH}-$ $\mathrm{H}_{2} \mathrm{O}=2: 5,4.0 \mathrm{~L}$ )를 실시하여 총 20개의 분획 (PGE-22-16-1PGE-22-16-20)을 얻었고, 화합물 4 (PGE-22-16-4, $7.3 \mathrm{mg}, \mathrm{Ve} /$ Vt $0.13-0.15$, ODS TLC $\mathrm{R}_{\mathrm{f}} 0.5, \mathrm{MeOH}-\mathrm{H}_{2} \mathrm{O}=1: 2$ )와 화합물 5 (PGE-22-16-17, $39.7 \mathrm{mg}, \mathrm{Ve} / \mathrm{Vt}$ 0.84-0.87, ODS TLC $\mathrm{R}_{\mathrm{f}}$ $0.5, \mathrm{MeOH}-\mathrm{H}_{2} \mathrm{O}=1: 1$ )를 얻었다.

화합물 1 (ginsenoside F1): 하얀색 가루 $(\mathrm{MeOH}) ;[\alpha]_{\mathrm{D}}^{25}+36.6^{\circ}$ (c 1.12, MeOH); positive FAB/MS $m / z 661.4[\mathrm{M}+\mathrm{Na}]^{+}$; IR $(\mathrm{KBr}, v) 3398,1660,1380,1080 \mathrm{~cm}^{-1}$; ${ }^{1} \mathrm{H}-\mathrm{NMR} \quad(400 \mathrm{MHz}$, $\left.\mathrm{C}_{5} \mathrm{D}_{5} \mathrm{~N}, \delta_{\mathrm{H}}\right) 5.22(1 \mathrm{H}, \mathrm{dd}, J=6.0,6.0 \mathrm{~Hz}, \mathrm{H}-24), 5.12(1 \mathrm{H}$, d, $\left.J=7.6 \mathrm{~Hz}, \mathrm{H}-1^{\prime}\right), 4.41$ (1H, br d, $J=11.6 \mathrm{~Hz}, \mathrm{H}-6$ 'a), 4.35 (1H, m, H-6), 4.25 (1H, dd, J=11.6, 4.4 Hz, H-6'b), 4.16 $\left(1 \mathrm{H}, \mathrm{m}, \mathrm{H}-3^{\prime}\right), 4.14$ (1H, m, H-12), 4.09 (1H, m, H-4'), $3.92\left(1 \mathrm{H}, \mathrm{dd}, J=8.4,7.6 \mathrm{~Hz}, \mathrm{H}-2^{\prime}\right), 3.86\left(1 \mathrm{H}, \mathrm{m}, \mathrm{H}-5^{\prime}\right)$, 3.47 (1H, dd, $J=10.8,4.4 \mathrm{~Hz}, \mathrm{H}-3), 2.49$ (1H, m, H-17), 2.46 (1H, overlapped, H-23a), 2.32 (1H, overlapped, H-22a), 2.22 (1H, overlapped, H-23b), $2.05(1 \mathrm{H}$, overlapped, H-11a), $1.94(1 \mathrm{H}, \mathrm{m}, \mathrm{H}-13), 1.91$ (3H, s, H-28), 1.88 (1H, overlapped, $\mathrm{H}-7 \mathrm{a}), 1.87(1 \mathrm{H}$, overlapped, H-2), $1.82(1 \mathrm{H}$, overlapped, H7b), $1.82(1 \mathrm{H}$, overlapped, $\mathrm{H}-16 \mathrm{a}), 1.78(1 \mathrm{H}$, overlapped, $\mathrm{H}-$ 22b), $1.70(1 \mathrm{H}$, overlapped, H-1a), $1.58(1 \mathrm{H}$, overlapped, H11b), 1.57 (1H, m, H-9), 1.57 (3H, s, H-26), 1.57 (3H, s, H-27), $1.56(3 \mathrm{H}, \mathrm{s}, \mathrm{H}-21), 1.50(1 \mathrm{H}$, overlapped, H-15a ), 1.39 (3H, s, H-29), 1.30 (1H, overlapped, H-16b), $1.17(1 \mathrm{H}$, 
d, $J=10.0 \mathrm{~Hz}, \mathrm{H}-5), 1.06$ (3H, s, H-18), 1.01 (1H, overlapped, $\mathrm{H}-1 \mathrm{~b}), 0.98$ (3H, s, H-19), 0.95 (1H, overlapped, H-15b), $0.94(3 \mathrm{H}, \mathrm{s}, \mathrm{H}-30) ;{ }^{13} \mathrm{C}-\mathrm{NMR}\left(100 \mathrm{MHz}, \mathrm{C}_{5} \mathrm{D}_{5} \mathrm{~N}, \delta_{\mathrm{C}}\right) 130.8$ (C-25), 125.8 (C-24), 98.1 (C-1'), 83.2 (C-20), 78.4 (C-3), 78.4 (C-3'), 78.0 (C-5'), 75.0 (C-2'), 71.6 (C-4'), 70.1 (C12), 67.7 (C-6), 62.8 (C-6'), 61.7 (C-5), 51.6 (C-17), 51.3 (C-14), 49.8 (C-9), 49.1 (C-13), 47.4 (C-7), 41.1 (C-8), 40.2 (C-4), 39.3 (C-1), 39.3 (C-10), 36.0 (C-22), 31.9 (C28), 30.8 (C-11), 30.7 (C-15), 28.0 (C-2), 26.5 (C-16), 25.6 (C-26), 23.1 (C-23), 22.3 (C-21), 17.7 (C-27), 17.5 (C-30), 17.3 (C-18), 17.3 (C-19), 16.4 (C-29).

화합물 2 (ginsenoside F2): 하얀색 가루 $(\mathrm{MeOH}) ;[\alpha]_{\mathrm{D}}^{25}+29.6^{\circ}$ (c 1.01, MeOH); positive $\mathrm{FAB} / \mathrm{MS} \mathrm{m} / \mathrm{z} 807.5[\mathrm{M}+\mathrm{Na}]^{+}$; IR (KBr, v) $3410,1657,1355,1080 \mathrm{~cm}^{-1}$; ${ }^{1} \mathrm{H}-\mathrm{NMR}$ (400 MHz, $\left.\mathrm{C}_{5} \mathrm{D}_{5} \mathrm{~N}, \delta_{\mathrm{H}}\right) 5.24(1 \mathrm{H}, \mathrm{dd}, J=6.8,6.4 \mathrm{~Hz}, \mathrm{H}-24), 5.20(1 \mathrm{H}$, d, $J=7.6 \mathrm{~Hz}, \mathrm{H}-1 "), 4.95(1 \mathrm{H}, \mathrm{d}, J=7.6 \mathrm{~Hz}, \mathrm{H}-1$ '), 4.54 (1H, dd, $J=11.2,2.4 \mathrm{~Hz}, \mathrm{H}-6 " \mathrm{a}), 4.44$ (1H, dd, $J=11.6,2.4$ Hz, H-6'a), 4.35 (1H, dd, $J=11.2,4.8 \mathrm{~Hz}, \mathrm{H}-6 " \mathrm{~b}), 4.28$ (1H, dd, $\left.J=11.6,5.6 \mathrm{~Hz}, \mathrm{H}-6^{\prime} \mathrm{b}\right), 4.20$ (1H, m, H-3'), 4.19 (1H, m, H-3"), 4.18 (1H, m, H-4"), 4.15 (1H, m, H-12), $4.13\left(1 \mathrm{H}, \mathrm{m}, \mathrm{H}-4^{\prime}\right), 4.03$ (1H, m, H-2"), 3.98 (1H, m, H2'), $3.95\left(1 \mathrm{H}, \mathrm{m}, \mathrm{H}-5^{\prime \prime}\right), 3.88\left(1 \mathrm{H}, \mathrm{m}, \mathrm{H}-5^{\prime}\right), 3.36(1 \mathrm{H}, \mathrm{dd}$, $J=11.6,4.0 \mathrm{~Hz}, \mathrm{H}-3), 2.54$ (1H, m, H-17), $2.48(1 \mathrm{H}$, overlapped, H-23a), 2.35 (1H, overlapped, H-22a), $2.24(1 \mathrm{H}$, overlapped, H-24b), 1.98 (1H, overlapped, H-11a), $1.97(1 \mathrm{H}$, m, H-13), 1.87 (1H, overlapped, H-2b), 1.84 (1H, overlapped, $\mathrm{H}-16 \mathrm{a}), 1.80$ (1H, overlapped, H-22b), 1.61 (3H, s, H-21), $1.60(1 \mathrm{H}$, overlapped, H-1a), $1.60(3 \mathrm{H}, \mathrm{s}, \mathrm{H}-26), 1.60(3 \mathrm{H}$, s, H-27), $1.59(1 \mathrm{H}$, overlapped, H-11b), $1.53(1 \mathrm{H}$, overlapped, H-6a), $1.50(1 \mathrm{H}$, overlapped, H-7a), $1.50(1 \mathrm{H}$, overlapped, H-15a), 1.42 (1H, overlapped, H-6b), 1.42 (1H, m, H-9), 1.38 (1H, overlapped, H-16b), 1.29 (3H, s, H-28), 1.20 (1H, overlapped, H-7b), 1.03 (1H, overlapped, H-15b), 0.99 (3H, s, H-29), 0.97 (3H, s, H-18), 0.96 (3H, s, H-30), 0.82 $(3 \mathrm{H}, \mathrm{s}, \mathrm{H}-19), 0.82(1 \mathrm{H}$, overlapped, H-1b), $0.75(1 \mathrm{H}, \mathrm{d}$,

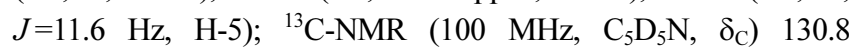
(C-25), 125.9 (C-24), 106.8 (C-1'), 98.4 (C-1"), 88.7 (C-3), 83.2 (C-20), 79.1 (C-3"), 78.6 (C-3'), 78.2 (C-5"), 78.1 (C5'), 75.7 (C-2"), 75.0 (C-2'), 71.9 (C-4"), 71.6 (C-4'), 63.0 (C-6"), 62.8 (C-6'), 56.4 (C-5), 50.1 (C-9), 49.4 (C-13), 40.0 (C-8), 39.6 (C-4), 39.2 (C-1), 36.9 (C-10), 36.1 (C22), 35.1 (C-7), 30.9 (C-15), 30.7 (C-11), 28.1 (C-28), 26.7 (C-2), 26.6 (C-16), 25.6 (C-26), 23.1 (C-23), 22.3 (C-21), 18.4 (C-6), 17.7 (C-27), 17.3 (C-30), 16.7 (C-29), 16.2 (C18), 15.9 (C-19), 15.6 (C-17), 15.4 (C-14).

화합물 3 (ginsenoside F3): 하얀색 가루 $(\mathrm{MeOH}) ;[\alpha]_{\mathrm{D}}^{25}+26.5^{\circ}$ (c $0.98, \mathrm{MeOH}$ ); positive $\mathrm{FAB} / \mathrm{MS} \mathrm{m} / \mathrm{z} 793.5 \quad[\mathrm{M}+\mathrm{Na}]^{+}$; infrared spectroscopy (IR) $(\mathrm{KBr}, v)$ 3469, 1655, 1462, 1076 $\mathrm{cm}^{-1}$; ${ }^{1} \mathrm{H}-\mathrm{NMR} \quad\left(400 \mathrm{MHz}, \mathrm{C}_{5} \mathrm{D}_{5} \mathrm{~N}, \quad \delta_{\mathrm{H}}\right) 5.29 \quad(1 \mathrm{H}, \quad \mathrm{dd}$, $J=6.4,5.6 \mathrm{~Hz}, \mathrm{H}-24), 5.05$ (1H, d, $\left.J=8.0 \mathrm{~Hz}, \mathrm{H}-1^{\prime}\right), 4.93$
(1H, d, $J=7.6 \mathrm{~Hz}, \mathrm{H}-1 "), 4.61(1 \mathrm{H}$, br d, $J=10.8 \mathrm{~Hz}, \mathrm{H}-$ 6'a), 4.39 (1H, m, H-3"), 4.37 (1H, m, H-6), 4.32 (1H, m, H-2"), 4.26 (1H, d, J=11.6 Hz, H-5"a), 4.19 (1H, m, H6'b), $4.16(1 \mathrm{H}, \mathrm{m}, \mathrm{H}-4 "), 4.11(1 \mathrm{H}, \mathrm{m}, \mathrm{H}-12), 4.08(1 \mathrm{H}$, m, H-3'), $3.99\left(1 \mathrm{H}, \mathrm{m}, \mathrm{H}-4^{\prime}\right), 3.97\left(1 \mathrm{H}, \mathrm{m}, \mathrm{H}-5^{\prime}\right), 3.84$ $\left(1 \mathrm{H}, \mathrm{dd}, J=8.0,8.0 \mathrm{~Hz}, \mathrm{H}-2^{\prime}\right), 3.74(1 \mathrm{H}$, br d, $J=11.6 \mathrm{~Hz}$, H-5"b) $3.46(1 \mathrm{H}, \mathrm{dd}, J=11.2,5.2 \mathrm{~Hz}, \mathrm{H}-3), 2.51 \quad(1 \mathrm{H}$, overlapped, H-23a) 2.49 (1H, m, H-17), 2.33 (1H, overlapped, H-23b) $2.31(1 \mathrm{H}$, overlapped, H-22a), 2.04 (1H, overlapped, H-11a), 1.95 (1H, m, H-13), 1.91 (3H, s, H-28), $1.88(1 \mathrm{H}$, overlapped, H-7a), 1.82 (1H, overlapped, H-2), $1.82(1 \mathrm{H}$, overlapped, H-7b), 1.80 (1H, overlapped, H-16a), $1.78(1 \mathrm{H}$, overlapped, H-22b), 1.68 (1H, overlapped, H-1a), $1.63(3 \mathrm{H}$, s, H-27), 1.60 (3H, s, H-21), $1.58(3 \mathrm{H}, \mathrm{s}, \mathrm{H}-26), 1.49(1 \mathrm{H}$, m, H-9), $1.47(1 \mathrm{H}$, overlapped, H-11b), $1.45(1 \mathrm{H}$, overlapped, H-15a), 1.38 (3H, s, H-29), 1.34 (1H, overlapped, H-16b), $1.16(1 \mathrm{H}, \mathrm{d}, J=10.0 \mathrm{~Hz}, \mathrm{H}-5), 1.06(3 \mathrm{H}, \mathrm{s}, \mathrm{H}-18), 0.98$ $(1 \mathrm{H}$, overlapped, H-1b), 0.97 (3H, s, H-19), 0.96 (1H, overlapped, $\mathrm{H}-15 \mathrm{~b}), \quad 0.92 \quad(3 \mathrm{H}, \quad \mathrm{s}, \quad \mathrm{H}-30) ;{ }^{13} \mathrm{C}-\mathrm{NMR} \quad(100$ $\left.\mathrm{MHz}, \mathrm{C}_{5} \mathrm{D}_{5} \mathrm{~N}, \delta_{\mathrm{C}}\right) 131.0$ (C-25), 125.8 (C-24), 104.4 (C-1"), 98.0 (C-1'), 83.4 (C-20), 79.0 (C-3'), 78.4 (C-3), 76.5 (C5'), 74.8 (C-2'), 73.9 (C-3"), 72.0 (C-4'), 71.7 (C-2"), 70.1 (C-12), 69.1 (C-4"), 68.3 (C-6'), 67.6 (C-6), 65.3 (C-5"), 61.6 (C-5), 51.6 (C-17), 51.2 (C-14), 49.8 (C-9), 49.0 (C13), 47.4 (C-7), 41.4 (C-8), 40.2 (C-4), 39.3 (C-1), 39.3 (C-10), 36.1 (C-22), 31.8 (C-28), 30.6 (C-11), 30.6 (C-15), 28.0 (C-2), 26.6 (C-16), 25.7 (C-26), 23.1 (C-23), 22.2 (C21), 17.8 (C-27), 17.5 (C-30), 17.3 (C-18), 17.3 (C-19), 16.4 (C-29).

화합물 4 (ginsenoside Ia): 하얀색 가루 $(\mathrm{MeOH})$; positive $\mathrm{FAB} / \mathrm{MS} \quad m / z \quad 823.5 \quad[\mathrm{M}+\mathrm{Na}]^{+}$; IR $(\mathrm{KBr}, v)$ 3401, 1649, 1462, $1076 \mathrm{~cm}^{-1} ; \quad{ }^{1} \mathrm{H}-\mathrm{NMR} \quad\left(400 \mathrm{MHz}, \mathrm{C}_{5} \mathrm{D}_{5} \mathrm{~N}, \quad \delta_{\mathrm{H}}\right) \quad 5.23$ $(1 \mathrm{H}, \mathrm{dd}, J=6.4,6.8 \mathrm{~Hz}, \mathrm{H}-24), 5.12(1 \mathrm{H}, \mathrm{d}, J=7.6 \mathrm{~Hz}, \mathrm{H}-$ 1"), $4.93\left(1 \mathrm{H}, \mathrm{d}, J=7.6 \mathrm{~Hz}, \mathrm{H}-1^{\prime}\right), 4.53$ (1H, overlapped, H-6"a), 4.42 (1H, dd, J=11.2, $2.4 \mathrm{~Hz}, \mathrm{H}-6 \mathrm{\prime}$ ), 4.29 (1H, m, H-6), 4.28 (1H, overlapped, H-3"), 4.25 (1H, dd, $J=11.2$, $5.6 \mathrm{~Hz}, \mathrm{H}-6 \mathrm{\prime}$ ) $), 4.24$ (1H, overlapped, H-4"), 4.21 (1H, m, H-3'), 4.14 (1H, m, H-12), $4.12(1 \mathrm{H}, \mathrm{m}, \mathrm{H}-4$ '), $4.11(1 \mathrm{H}$, overlapped, H-6"b), 4.08 (1H, overlapped, H-2"), $3.97(1 \mathrm{H}$, m, H-2'), 3.87 (1H, overlapped, H-5"), 3.83 (1H, m, H-5'), $3.42(1 \mathrm{H}, \mathrm{dd}, J=4.4,10.8 \mathrm{~Hz}, \mathrm{H}-3), 2.48$ (1H, m, H-17), 2.47 (1H, overlapped, H-23a), 2.31 (1H, overlapped, H-22a), 2.24 (1H, overlapped, H-23b), $2.06(1 \mathrm{H}$, overlapped, H-11a), $2.00(3 \mathrm{H}, \mathrm{s}, \mathrm{H}-28), 1.95(1 \mathrm{H}, \mathrm{m}, \mathrm{H}-13), 1.88$ (1H, overlapped, $\mathrm{H}-7 \mathrm{a}), 1.87(2 \mathrm{H}$, overlapped, $\mathrm{H}-2), 1.85(1 \mathrm{H}$, overlapped, H7b), $1.83(1 \mathrm{H}$, overlapped, H-16a), $1.75(1 \mathrm{H}$, overlapped, H22b), $1.71(1 \mathrm{H}$, overlapped, H-1a), $1.58(1 \mathrm{H}$, overlapped, H11b), 1.57 (1H, m, H-9), 1.57 (3H, s, H-21), 1.57 (3H, s, H-26), 1.57 (3H, s, H-27), 1.51 (1H, overlapped, H-15a), $1.36(3 \mathrm{H}, \mathrm{s}, \mathrm{H}-29), 1.34$ (1H, overlapped, H-16b), 1.20 (1H, d, J=10.0 Hz, H-5), 1.06 (3H, s, H-18), 1.01 (1H, 
overlapped, H-1b), 0.96 (3H, s, H-30), 0.91 (3H, s, H-19); ${ }^{13} \mathrm{C}-\mathrm{NMR}\left(100 \mathrm{MHz}, \mathrm{C}_{5} \mathrm{D}_{5} \mathrm{~N}, \quad \delta_{\mathrm{C}}\right) 130.8(\mathrm{C}-25), 125.8(\mathrm{C}-$ 24), 107.1 (C-1"), 98.1 (C-1'), 88.8 (C-3), 83.2 (C-20), 78.2 (C-3"), 78.6 (C-3'), 78.2 (C-5'), 78.1 (C-5"), 75.8 (C-2'), 75.0 (C-2"), 71.9 (C-4'), 71.6 (C-4"), 70.1 (C-12), 67.5 (C6), 63.1 (C-6'), 62.8 (C-6"), 61.7 (C-5), 51.5 (C-17), 51.3 (C-14), 49.7 (C-9), 49.1 (C-13), 47.4 (C-7), 41.1 (C-8), 40.4 (C-4), 39.1 (C-1), 38.8 (C-10), 36.0 (C-22), 31.3 (C28), 30.8 (C-11), 30.7 (C-15), 26.5 (C-16), 26.5 (C-2), 25.6 (C-26), 23.1 (C-23), 22.3 (C-21), 17.7 (C-27), 17.5 (C-18), 17.4 (C-19), 17.3 (C-30), 16.9 (C-29).

화합물 5 (notoginsenoside $\mathrm{Fe}$ ): 하얀색 가루 $(\mathrm{MeOH})$; positive $\mathrm{FAB} / \mathrm{MS} \quad m / z \quad 939.5 \quad[\mathrm{M}+\mathrm{Na}]^{+}$; IR $(\mathrm{KBr}, v)$ 3401, 1649, 1462, $1076 \mathrm{~cm}^{-1} ; \quad{ }^{1} \mathrm{H}-\mathrm{NMR} \quad\left(400 \mathrm{MHz}, \mathrm{C}_{5} \mathrm{D}_{5} \mathrm{~N}, \quad \delta_{\mathrm{H}}\right) \quad 5.59$ (1H, br s, H-1"'), $5.24(1 \mathrm{H}, \mathrm{dd}, J=6.8,6.4 \mathrm{~Hz}, \mathrm{H}-24), 5.06$ $\left(1 \mathrm{H}, \mathrm{d}, J=7.6 \mathrm{~Hz}, \mathrm{H}-1^{\prime \prime}\right), 4.87\left(1 \mathrm{H}, \mathrm{d}, J=7.6 \mathrm{~Hz}, \mathrm{H}-1^{\prime}\right)$, $4.78\left(1 \mathrm{H}, \mathrm{m}, \mathrm{H}-2^{2 \prime \prime}\right), 4.72\left(1 \mathrm{H}, \mathrm{m}, \mathrm{H}-3^{\prime \prime \prime}\right), 4.68(1 \mathrm{H}, \mathrm{m}, \mathrm{H}-$ 4"'), 4.59 (1H, br d, H-6"a), $4.28(1 \mathrm{H}, \mathrm{dd}, J=11.6,5.6 \mathrm{~Hz}$, H-6'b), 4.25 (1H, dd, $J=12.0,2.4 \mathrm{~Hz}, \mathrm{H}-5$ "'a), $4.23(1 \mathrm{H}$, m, H-5"'b), 4.20 (1H, m, H-3'), 4.19 (1H, m, H-3"), 4.18 (1H, m, H-4"), 4.15 (1H, m, H-12), 4.13 (1H, m, H-4'), $4.03\left(1 \mathrm{H}, \mathrm{m}, \mathrm{H}-2^{\prime \prime}\right), 4.00(1 \mathrm{H}, \mathrm{m}, \mathrm{H}-6 " \mathrm{~b}), 3.98(1 \mathrm{H}, \mathrm{m}, \mathrm{H}-$ 2'), $3.95(1 \mathrm{H}, \mathrm{m}, \mathrm{H}-5 "), 3.88\left(1 \mathrm{H}, \mathrm{m}, \mathrm{H}-5^{\prime}\right), 3.36(1 \mathrm{H}, \mathrm{dd}$, $J=11.6,4.0 \mathrm{~Hz}, \mathrm{H}-3), 2.54$ (1H, m, H-17), $2.48(1 \mathrm{H}$, overlapped, H-23a), 2.35 (1H, overlapped, H-22a), $2.24(1 \mathrm{H}$, overlapped, H-24b), 1.98 (1H, overlapped, H-11a), $1.97(1 \mathrm{H}$, m, H-13), 1.87 (1H, overlapped, H-2b), 1.84 (1H, overlapped, H-16a), 1.80 (1H, overlapped, H-22b), 1.61 (3H, s, H-21), $1.60(1 \mathrm{H}$, overlapped, H-1a), $1.60(3 \mathrm{H}, \mathrm{s}, \mathrm{H}-26), 1.60(3 \mathrm{H}$, s, H-27), 1.59 (1H, overlapped, H-11b), $1.53(1 \mathrm{H}$, overlapped, H-6a), 1.50 (1H, overlapped, H-7a), 1.50 (1H, overlapped, H-15a), 1.42 (1H, overlapped, H-6b), 1.42 (1H, m, H-9), 1.38 (1H, overlapped, H-16b), 1.29 (3H, s, H-28), 1.20 (1H, overlapped, H-7b), 1.03 (1H, overlapped, H-15b), 0.99 (3H, s, H-29), 0.97 (3H, s, H-18), 0.96 (3H, s, H-30), 0.82 $(3 \mathrm{H}, \mathrm{s}, \mathrm{H}-19), 0.82(1 \mathrm{H}$, overlapped, H-1b), $0.75(1 \mathrm{H}, \mathrm{d}$, $J=11.6 \mathrm{~Hz}, \mathrm{H}-5) ;{ }^{13} \mathrm{C}-\mathrm{NMR}\left(100 \mathrm{MHz}, \mathrm{C}_{5} \mathrm{D}_{5} \mathrm{~N}, \delta_{\mathrm{C}}\right) 130.9$ (C-25), 125.9 (C-24), 110.0 (C-1"'), 106.8 (C-1'), 97.9 (C1"), 88.8 (C-3), 86.1 (C-4"'), 83.1 (C-2"'), 83.1 (C-20), 79.1 (C-3'), 78.8 (C-3"'), 78.8 (C-3"), 78.2 (C-5'), 76.4 (C-5"), 75.7 (C-2'), 74.9 (C-2"), 72.0 (C-4'), 71.9 (C-4"), 70.2 (C12), 68.4 (C-6"), 63.1 (C-6'), 62.6 (C-5"'), 56.4 (C-5), 51.6 (C-17), 51.4 (C-14), 50.1 (C-9), 49.4 (C-13), 39.9 (C-8), 39.6 (C-4), 39.2 (C-1), 36.9 (C-10), 36.1 (C-22), 35.1 (C7), 30.7 (C-15), 30.7 (C-11), 28.1 (C-28), 26.7 (C-2), 26.6 (C-16), 25.7 (C-26), 23.1 (C-23), 22.3 (C-21), 18.4 (C-6), 17.8 (C-27), 17.3 (C-30), 16.7 (C-29), 16.2 (C-18), 15.9 (C$19)$.

\section{세포배양}

대장암(human colon adenocarcinoma; HCT-116), 난소암(human ovarian adenocarcinoma; SK-OV-3), 자궁암(human cervix adenocarcinoma; HeLa), 간암(human hepatoma; HepG2) 및 피부암 (human melanoma; SK-MEL-5)은 한국 세포주 은행 (KCLB, Seoul, Korea)에서 제공받았다. 세포독성 측정을 위한 세포주는 $10 \% \mathrm{FBS}$ 와 $1 \%$ penicillin-streptomycin이 첨가된 RPMI 1640 배지를 사용하여, $5 \% \mathrm{CO}_{2}, 37^{\circ} \mathrm{C}$ 조건에서 배양하였다.

\section{세포독성}

인삼 열매로부터 분리한 화합물들의 세포독성 실험은 Skehan 등의 연구[12] MTT colorimetric assay 방법으로 진행하였다. 배양된 cello에 RPMI-1640 배지와 분리한 다섯 종의 ginsenoside를 각각 $6.25,12.5,25.0,50.0,75.0$, 및 $100.0 \mu \mathrm{M}$ 의 농도 별로 잘 혼합하여 seeding 하였으며, cell수를 $1 \times 10^{4}$ cells $/ \mathrm{mL}$ 로 조정 하였다. 준비한 cell을 plate에 $100 \mu \mathrm{L}$ 씩 첨가하고 12시간 배양 하였다. 배양 후 각 cell에 $50 \mu \mathrm{L}$ 의 MTT $[5 \mathrm{mg} / \mathrm{mL}$ in phosphate buffered saline] 시약을 첨가하여 $37^{\circ} \mathrm{C}$ 에서 다시 2시간 동안 배 양하였다. 배양이 종료된 후, 배지를 제거하고 $100 \mu \mathrm{L}$ 의 $\mathrm{DMSO}$ 를 첨가하여 용해시켰다. Cell plate reader (Bio-Rad Co., Westbury, NY, USA)로 $550 \mathrm{~nm}$ 에서 흡광도를 측정하였다. 세포 증식 억제효과는 다음과 같이 계산하였다.

\section{Cell viability (\%)}

$=[\mathrm{OD}($ compound $)-\mathrm{OD}($ Blank $) / \mathrm{OD}($ Control $)-\mathrm{OD}($ Blank $)] \times 100$

\section{결과 및 고찰}

화합물 1은 positive $\mathrm{FAB} / \mathrm{MS}$ 에서 $m / z 661.4[\mathrm{M}+\mathrm{Na}]^{+}$의 분자 이온 peak가 관측되어 분자량을 638로 결정하였다. IR 스펙트 럼으로부터 수산기 $\left(3398 \mathrm{~cm}^{-1}\right)$ 와 이중결합 $\left(1660 \mathrm{~cm}^{-1}\right)$ 이 있는 것 으로 확인되었다. ${ }^{1} \mathrm{H}-\mathrm{NMR}$ 스펙트럼에서8개의 methyl proton signal $\left[\delta_{\mathrm{H}} 1.91(3 \mathrm{H}, \mathrm{s}, \mathrm{H}-28), 1.57(3 \mathrm{H}, \mathrm{s}, \mathrm{H}-26), 1.57\right.$ (3H, s, H-27), 1.56 (3H, s, H-21), 1.39 (3H, s, H-29), 1.06 $(3 \mathrm{H}, \mathrm{s}, \mathrm{H}-18), 0.98(3 \mathrm{H}, \mathrm{s}, \mathrm{H}-19), 0.94(3 \mathrm{H}, \mathrm{s}, \mathrm{H}-30)]$ 로부 터 화합물 1의 aglycone이 4개의 환을 가지는 tetracyclic triterpene, 즉 dammarane 골격임을 예상하였다. Shen 등의 연구[13]에서 일반적으로 28 번 proton signal은 $\delta_{\mathrm{H}} 1.30$ 에서 관측되는데, 해당 화합물의 경우 $\delta_{\mathrm{H}} 1.91$ 까지 저자장으로 이동하는 것을 알 수 있 었다. 따라서, 이 화합물이 protopanaxatriol (PPT)-type인 것을 예상하였다. 또한 한 개의 olefin methine proton signal $\left[\delta_{\mathrm{H}}\right.$ $5.22(1 \mathrm{H}, \mathrm{dd}, J=6.0,6.0 \mathrm{~Hz}, \mathrm{H}-24)]$ 과, 세개의 oxygenated methine proton signal $\left[\delta_{\mathrm{H}} 4.35(1 \mathrm{H}, \mathrm{m}, \mathrm{H}-6), 4.14(1 \mathrm{H}, \mathrm{m}\right.$, $\mathrm{H}-12), 3.47(1 \mathrm{H}, \mathrm{dd}, J=10.8,4.4 \mathrm{~Hz}, \mathrm{H}-3)]$ 을 관측하였으며, 1 개의 hemiacetal proton signal $\left[\ddot{a}_{\mathrm{H}} 5.12(1 \mathrm{H}, \mathrm{d}, J=7.6 \mathrm{~Hz}\right.$, $\left.\left.\mathrm{H}-1^{\prime}\right)\right]$ 과 4 개의 oxygenated methine proton signal $\left[\delta_{\mathrm{H}} 4.16\right.$ $\left(1 \mathrm{H}, \mathrm{m}, \mathrm{H}-3^{\prime}\right), 4.09\left(1 \mathrm{H}, \mathrm{m}, \mathrm{H}-4^{\prime}\right), 3.92(1 \mathrm{H}, \mathrm{dd}, J=8.4$, $\left.7.6 \mathrm{~Hz}, \mathrm{H}-2^{\prime}\right), 3.86\left(1 \mathrm{H}, \mathrm{m}, \mathrm{H}-5^{\prime}\right)$ ]과 1 개의 oxygenated methylene proton signal $\left[\delta_{\mathrm{H}} 4.41(1 \mathrm{H}\right.$, br d, $J=11.6 \mathrm{~Hz}, \mathrm{H}-$ 6 'a), $\left.4.25\left(1 \mathrm{H}, \mathrm{dd}, J=11.6,4.4 \mathrm{~Hz}, \mathrm{H}-6^{\prime} \mathrm{b}\right)\right]$ 로부터 한 개의 육탄당이 존재함을 알 수 있었다. Anomer proton signal의 결 합 정수 $(J=7.6 \mathrm{~Hz})$ 로부터 당의 1 번과 2 번 수소가 서로 axialaxial 형태를 이루는 것을 알 수 있었으며, 이를 통해 이 화합 


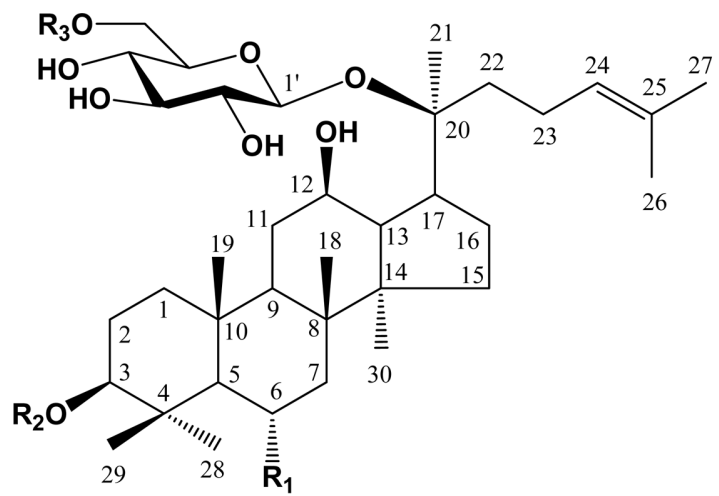

\begin{tabular}{cccc} 
& $\mathrm{R}_{1}$ & $\mathrm{R}_{2}$ & $\mathrm{R}_{3}$ \\
\hline ginsenoside F1 (1) & $\mathrm{OH}$ & $\mathrm{H}$ & $\mathrm{H}$ \\
ginsenoside F2 (2) & $\mathrm{H}$ & $\beta$-glc & $\mathrm{H}$ \\
ginsenoside F3 (3) & $\mathrm{OH}$ & $\mathrm{H}$ & $\alpha$-ara (p) \\
ginsenoside Ia (4) & $\mathrm{OH}$ & $\beta$-glc & $\mathrm{H}$ \\
notoginsenoside Fe (5) & $\mathrm{H}$ & $\beta$-glc & $\alpha$-ara (f) \\
\hline
\end{tabular}

* $\beta$-glc: $\beta$-D-glucopyranose, $\alpha$-ara (p): $\alpha$-L-arabinopyranose, $\alpha$-ara -(f): $\alpha$-L-arabinofuranose

Fig. 1 Chemical structures of ginsenosides 1-5 from the fruits of Panax ginseng

물이 PPT-type dammarane triterpene monoglycoside임을 예상 하였다. ${ }^{13} \mathrm{C}-\mathrm{NMR}$ 스펙트럼에서 당 유래 signal을 제외한 총 카 본 수는 30 개로 ${ }^{1} \mathrm{H}-\mathrm{NMR}$ 에서 예상한 triterpenoid임이 확인되었 다. 이때 당으로부터 유래한 1 개의 hemiacetal $\delta_{\mathrm{C}} 98.1$ (C-1'), 4개의 oxygenated methine $\left[\delta_{\mathrm{C}} 78.4\left(\mathrm{C}-3^{\prime}\right), 78.0\right.$ (C-5'), 75.0 $\left(\mathrm{C}-2^{\prime}\right), 71.6\left(\mathrm{C}-4^{\prime}\right)$ ], 1개의 oxygenated methylene $\delta_{\mathrm{C}} 62.8$ (C$\left.6^{\prime}\right)$ carbon signal결과와 구성당의 ${ }^{1} \mathrm{H}-\mathrm{NMR}$ 및 $\mathrm{HSQC}$ 를 종합분 석하여 이 당이 $\beta$-glucopyranose임을 확인하였다. 한 개의 olefin quaternary carbon signal $\delta_{\mathrm{C}} 130.8$ (C-25), 한 개의 olefin methine carbon signal $\delta_{\mathrm{C}} 125.8(\mathrm{C}-24)$, 한 개의 oxygenated quaternary carbon signal $\delta_{\mathrm{C}} 83.2(\mathrm{C}-20)$, 3 개의 oxygenated methine carbon signal $\left[\delta_{\mathrm{C}} 78.4\right.$ (C-3), 70.1 (C12), 67.7 (C-6)], 4개의 quaternary carbon signal [ $\delta_{\mathrm{C}} 51.3$ (C-14), 41.1 (C-8), 40.2 (C-4), 39.3 (C-10)], 4개의 methine carbon signal $\left[\delta_{\mathrm{C}} 61.7\right.$ (C-5), 51.6 (C-17), 49.8 (C-9), 49.1 (C-13)], 8개의 methylene carbon signal $\left[\delta_{\mathrm{C}} 47.4\right.$ (C-7), 39.3 (C-1), 36.0 (C-22), 30.8 (C-11), 30.7(C-15), 28.0 (C-2), 26.5 (C-16), 23.1 (C-23)], 8개의 methyl carbon signal [ $\delta_{\mathrm{C}} 31.9$ (C-28), 25.6 (C-26), 22.3 (C-21), 17.7 (C-27), 17.5 (C-30), 17.3 (C-18), 17.3 (C-19), 16.4 (C-29)]을 관측하여, $\mathrm{Wu}$ 등의 연구 [14]에서 보고된 문헌 값과 비교하여 PPT-type임을 확인하 였다. 또한 Peng 등의 연구[15]에서 C-20의 carbon signal은 대 개 $72.9 \mathrm{ppm}$ 에서 관측되나, $\delta_{\mathrm{C}} 83.2$ 까지 저자장으로 이동한 것 으로 보아 $\beta$-D-glucopyranose가 C-20의 수산기와 결합하여 glycosidation shift가 일어난 것임을 알 수 있었다. $\mathrm{gHMBC}$ 스 펙트럼에서 glucopyranose의 anomer proton signal $\delta_{\mathrm{H}} 5.12$ $\left(\mathrm{H}-1^{\prime}\right)$ 이 aglycone의 oxygenated quaternary carbon signal $\delta_{\mathrm{C}}$ 83.2 (C-20)과 cross peak를 보여 glucopyranose가 20번 수산기
에 결합하는 것을 확인하였다. 두개의 methyl proton signal $\left[\delta_{\mathrm{H}}\right.$ 1.57 (3H, s, H-26), 1.57 (3H, s, H-27)]이 olefin methine carbon signal $\delta_{\mathrm{H}} 5.22(1 \mathrm{H}, \mathrm{dd}, J=6.0,6.0 \mathrm{~Hz}, \mathrm{H}-24)$ 과 cross peak가 확인되어 이중결합의 결합 위치를 결정하였다. 위 결과를 종합하여, 화합물 $\mathbf{1}$ 을 $\mathrm{Su}$ 등 [16]이 보고한 문헌과 비 교 분석한 결과, ginsenoside $\mathrm{F} 1$ 으로 구조 동정하였다.

화합물 2는 positive FAB-MS에서 $m / z \quad 807.5[\mathrm{M}+\mathrm{Na}]^{+}$의 분 자이온 peak가 관측되어 분자량을 784 로 결정하였다. IR 스펙 트럼으로부터 수산기 $\left(3410 \mathrm{~cm}^{-1}\right)$ 와 이중결 $\left(1657 \mathrm{~cm}^{-1}\right)$ 이 있는 것으로 확인되었다. 화합물 1 과의 분자량 차이가 146 인 것으로 보아 수산기가 하나 빠지고 육탄당이 하나 더 존재함을 예상하 였다. NMR 데이터는 추가된 육탄당을 제외한 나머지 signal들 이 화합물 1과 매우 유사한 값을 가지는 것을 확인하였다. 다 만 NMR 스펙트럼에서 화합물 1과 비교하여 oxygenated methine signal이 사라지고 methylene signal $\left[\delta_{\mathrm{H}} 1.53(1 \mathrm{H}\right.$, $\mathrm{H}-6 \mathrm{a}), 1.42(1 \mathrm{H}, \mathrm{H}-6 \mathrm{~b}) ; \delta_{\mathrm{C}} 18.4$ (C-6)]이 관측됨에 따라 이 화합물의 aglycone이 protopanaxadiol (PPD)-type인 것을 예상 하였다. ${ }^{13} \mathrm{C}-\mathrm{NMR}$ 스펙트럼에서 당으로부터 유래한 1 개의 hemiacetal carbon signal $\ddot{a}_{\mathrm{C}} 98.4$ (C-1"), 4개의 oxygenated methine $\left[\delta_{\mathrm{C}} 79.1(\mathrm{C}-3 "), 78.2\left(\mathrm{C}-5^{\prime \prime}\right), 75.7\right.$ (C-2"), 71.9 (C$4 ")]$, 1 개의 oxygenated methylene $\delta_{\mathrm{C}} 63.0$ (C-6") carbon signal이 추가로 관측됨에 따라, 이 당이 $\beta$-glucopyranose임을 확인하였다. 또한 Peng 등의 연구[15]에서 C-3 signal은 대개 $78.5 \mathrm{ppm}$ 에서 관측되나, $\delta_{\mathrm{C}} 88.7$ 까지 저자장으로 이동한 것으 로 보아 $\beta$-D-glucopyranose가 C-3에 위치할 것으로 예상되었고, gHMBC 스펙트럼에서 glucopyranose의 anomer proton signal $\delta_{\mathrm{H}} 5.20(\mathrm{H}-1 ")$ 이 aglycone의 oxygenated methine carbon signal $\delta_{\mathrm{C}} 88.7$ (C-3)과 cross peak를 보여 glucopyranose가 3 번 수산기에 결합하는 것을 다시 한번 확인하였다. 위 결과를 종합하여 화합물 2를 Yang 등 [17]이 보고한 ginsenoside F2로 구조 동정하였다.

화합물 3은 positive $\mathrm{FAB} / \mathrm{MS}$ 에서 $m / z \quad 793.5[\mathrm{M}+\mathrm{Na}]^{+}$의 분자이온 peak가 관측되어 분자량을 770 으로 결정하였다. IR 스 펙트럼으로부터 수산기 $\left(3469 \mathrm{~cm}^{-1}\right)$ 와 이중결합 $\left(1655 \mathrm{~cm}^{-1}\right)$ 이 있 는 것으로 확인되었다. 화합물 1 과의 분자량 차이가 132 인 것 으로 보아 오탄당이 하나 더 존재함을 예상하였다. NMR 데이 터는 추가된 오탄당을 제외한 나머지 signal들이 화합물 1과 매 우 유사한 값을 가지는 것을 확인하였다. ${ }^{13} \mathrm{C}-\mathrm{NMR}$ 스펙트럼에 서 당으로부터 유래한 1 개의 hemiacetal carbon signal $\delta_{\mathrm{C}}$ 104.4 (C-1"), 3개의 oxygenated methine [ $\delta_{\mathrm{C}} 73.9$ (C-3"), 71.7 (C-2"), 69.1 (C-4")], 1개의 oxygenated methylene $\delta_{\mathrm{C}}$ 65.3 (C-5") carbon signal이 추가로 관측됨에 따라, 추가로 결 합한 당이 $\alpha$-arabinopyranose임을 확인하였다. 또한 $\mathrm{Seo}$ 등의 연구[18]에서 C-6' carbon signal은 대개 $62.5 \mathrm{ppm}$ 에서 관측되나, $\delta_{\mathrm{C}} 68.3$ 까지 저자장으로 이동한 것으로 보아 $\alpha$-L-arabinopyranose 가 C-6'의 수산기와 결합하여 glycosidation shift가 일어난 것임 을 알 수 있었다. gHMBC 스펙트럼에서 arabinopyranose의 anomer proton signal $\delta_{\mathrm{H}} 4.93\left(\mathrm{H}-1^{\prime \prime}\right)$ 이 glucopyranose의 oxygenated methylene carbon signal $\delta_{\mathrm{C}} 68.3$ (C-6')과 cross peak를 보여 arabinopyranose가 $6^{\prime}$ 번 수산기에 결합하는 것을 다시 한번 확 인하였다. 위 결과를 종합하여 화합물 3 을 ginsenoside F3 로 구조 동정 하였고, $\mathrm{Li}$ 등의 연구[19]에서 보고된 문헌 값과 비 

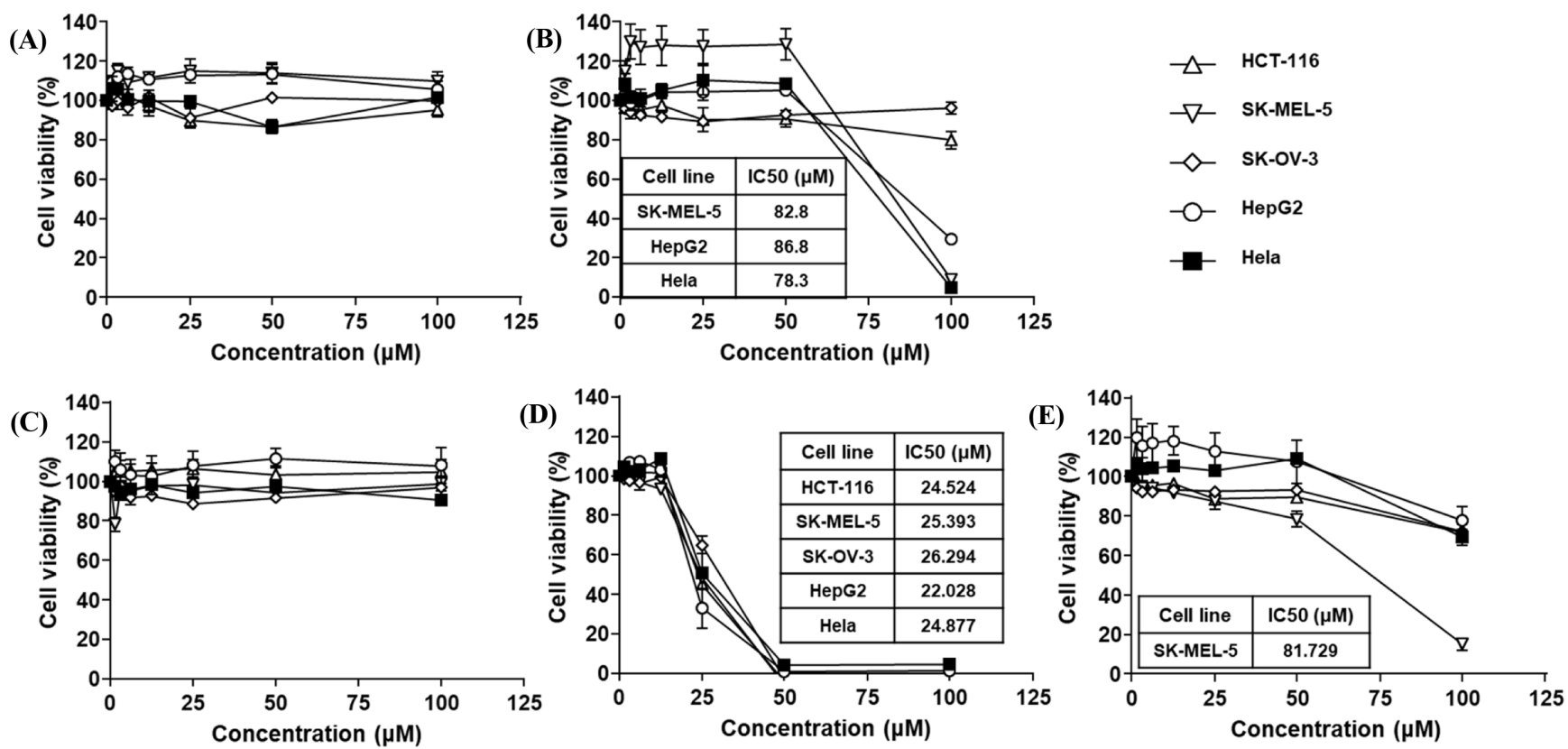

Fig. 2 The cytotoxicity of ginsenosides 1-5 isolated from the fruits of Panax ginseng against. HCT-116, SK-OV-3, HeLa, HepG2, SK-MEL-5 cancer cell lines. A: ginsenoside F1, B: ginsenoside F2, C: ginsenoside F3, D: ginsenoside Ia, E: notoginsenoside Fe

교하였다.

화합물 4는 positive $\mathrm{FAB} / \mathrm{MS}$ 에서 $m / z \quad 823.5[\mathrm{M}+\mathrm{Na}]^{+}$의 분 자이온 peak가 관측되어 분자량을 800 으로 결정하였다. IR 스 펙트럼으로부터 수산기 $\left(3401 \mathrm{~cm}^{-1}\right)$ 와 이중결합 $\left(1649 \mathrm{~cm}^{-1}\right)$ 이 있 는 것으로 확인되었다. 화합물 1 과의 분자량 차이가 162 인 것 으로 보아 육탄당이 하나 더 존재함을 예상하였다. NMR 데이 터는 추가된 육탄당을 제외한 나머지 signal들이 화합물 1과 유 사한 값을 가지는 것을 확인하였다. ${ }^{13} \mathrm{C}-\mathrm{NMR}$ 스펙트럼에서 당 으로부터 유래한1개의 hemiacetal carbon signal $\delta_{\mathrm{C}} 107.1$ (C$1 ")$, 4개의 oxygenated methine $\left[\delta_{\mathrm{C}} 78.2\right.$ (C-3"), 78.1 (C-5"), $\left.75.0\left(\mathrm{C}-2^{\prime \prime}\right), 71.6\left(\mathrm{C}-4^{\prime \prime}\right)\right]$, 1개의 oxygenated methylene $\delta_{\mathrm{C}}$ 62.8 (C-6") carbon signal이 추가로 관측됨에 따라, 추가로 결 합한 당이 $\beta$-glucopyranose임을 확인하였다. 또한 Peng 등의 연 구[15]에서 C-3, C-20의 carbon signal은 대개 78.5, $72.9 \mathrm{ppm}$ 에서 관측되나, $\delta_{\mathrm{C}} 88.8,83.2$ 까지 저자장으로 이동한 것으로 보 아 $\beta$-D-glucopyranose가 각각 C-3과 C- 20 의 수산기에 결합하여 glycosidation shift가 일어난 것임을 알 수 있었다. $\mathrm{gHMBC}$ 스 펙트럼에서 glucopyranose의 anomer proton signal $\delta_{\mathrm{H}} 5.12, \mathrm{~d}$, $J=7.8 \mathrm{~Hz}$, (H-1")이 aglycone의 oxygenated methylene carbon signal $\delta_{\mathrm{C}} 90.8$ (C-3)과 cross peak를 보여 glucopyranose가 3 번 수산기에 결합하는 것을 다시 한번 확인하였다. 위 결과를 종합하여 화합물 $\mathbf{4}$ 를 ginsenoside $\mathrm{Ia}$ 로 구조 동정 하였고, Dou 등의 연구[20]에서 보고된 문헌 값과 비교하였다.

화합물 5는 positive $\mathrm{FAB} / \mathrm{MS}$ 에서 $\mathrm{m} / \mathrm{z} 939.5[\mathrm{M}+\mathrm{Na}]^{+}$의 분자이온 peak가 관측되어 분자량을 917 로 결정하였다. IR 스 펙트럼으로부터 수산기 $\left(3401 \mathrm{~cm}^{-1}\right)$ 와 이중결합 $\left(1649 \mathrm{~cm}^{-1}\right)$ 이 있 는 것으로 확인되었다. 화합물 $\mathbf{2}$ 와의 분자량 차이가 133 인 것 으로 보아 오탄당이 하나 더 존재함을 예상하였다. NMR 데이 터는 추가된 오탄당을 제외한 나머지 signal들이 화합물 2 와 유
사한 값을 가지는 것을 확인하였다. ${ }^{13} \mathrm{C}-\mathrm{NMR}$ 스펙트럼에서 당 으로부터 유래한 1개의 hemiacetal carbon $\delta_{\mathrm{C}} 110.0$ (C-1"'), 3 개의 oxygenated methine [ $\delta_{\mathrm{C}} 86.1$ (C-4"'), 83.1 (C-2"'), 78.8 $\left.\left(\mathrm{C}-3{ }^{\prime \prime \prime}\right)\right]$, 1 개의 oxygenated methylene $\delta_{\mathrm{C}} 62.6$ (C-5"') carbon signal이 추가로 관측됨에 따라, 추가로 결합한 당이 $\alpha$ arabinofuranose임을 확인하였다. 또한 $\mathrm{Seo}$ 등의 연구[18]에서 C-6" carbon signal은 대개 $62.5 \mathrm{ppm}$ 에서 관측되나, $\delta_{\mathrm{C}} 68.4$ 까 지 저자장으로 이동한 것으로 보아 $\alpha$-L-arabinofuranose가 C-6" 에 위치함을 예상하였고, $\mathrm{gHMBC}$ 스펙트럼에서 arabinofuranose 의 anomer proton signal $\delta_{\mathrm{H}} 5.59\left(\mathrm{H}-1{ }^{\prime \prime \prime}\right)$ 이 $\beta$-glucopyranose의 oxygenated methylene carbon signal $\delta_{\mathrm{C}} 68.4$ (C-6")과 cross peak를 보여 arabinofuranose가 6"번 수산기에 결합하는 것을 다 시 한번 확인하였다. 위 결과를 종합하여 화합물 5는 Wang 등 [21]이 보고한, notoginsenoside $\mathrm{Fe}$ 로 구조결정하였다. 그러나, 화 합물 2-5는 인삼열매에서는 이번에 처음 분리 보고되었다.

인삼 열매로부터 분리한 5 종의 화합물을 5 종의 인체 암세포 주(HCT-116, SK-OV-3, HeLa, HepG2, SK-MEL-5)에 처리하 여 세포독성을 측정하였다(Fig. 2). Ginsenoside F2는 SK-MEL$5(82.8 \mu \mathrm{M}), \mathrm{HepG} 2(86.8 \mu \mathrm{M}), \mathrm{HeLa}(78.3 \mu \mathrm{M})$ 농도에서 각 암세포주의 세포 생존율이 $50 \%$ 이하로 감소하였다. Ginsenoside Ia는 HCT-116 (24.5 $\mu \mathrm{M})$, SK-MEL-5 (25.4 $\mu \mathrm{M})$, SK-OV-3 (26.3 $\mu \mathrm{M})$, HepG2 $(22.0 \mu \mathrm{M})$, HeLa $(24.9 \mu \mathrm{M})$ 농도에서 각 암세포 주의 세포 생존율이 $50 \%$ 이하로 감소하였다. Notoginsenoside $\mathrm{Fe}$ 는 SK-MEL-5: $81.7 \mu \mathrm{M}$ 농도에서 각 암세포주의 세포 생존 율이 $50 \%$ 이하로 감소하였다. 위 결과에 따르면 ginsenoside Ia 는 5 종의 모든 인체 암세포주에 대해 세포독성이 있었으며, ginsenoside F2는 피부암, 간암 및 자궁암에, notoginsenoside $\mathrm{Fe}$ 는 피부암에 대한 세포독성이 나타났다. 화합물 $2,4,5$ 의 구 조 모두 3 번 수산기에 glucopyranose가 결합 되어있는 것을 확 
인하였고, 위 결과에 따라 3 번 수산기에 당이 결합되면 인체 암 세포주에 대해 세포독성이 나타나는 것을 알 수 있었다. 실험 을 통해 인삼 열매로부터 분리한 5종의 ginsenoside가 인체 암 세포주에 대해 세포독성을 저해시키는 것을 확인하였다.

\section{초 록}

인삼(Panax. ginseng) 열매를 $80 \% \mathrm{MeOH}$ 수용액으로 3회 반 복 추출한 뒤, 감압 농축한 추출물을 EtOAc, $n-\mathrm{BuOH}$ 과 $\mathrm{H}_{2} \mathrm{O}$ 층으로 계통 분획을 실시하였다. $\mathrm{EtOAc}$ 분획에 대하여 $\mathrm{SiO}_{2}$ 및 ODS column chromatography를 반복실시하여 5종의 ginsenoside 화합물을 분리 및 정제하였다. $\mathrm{NMR}, \mathrm{IR}, \mathrm{FAB} / \mathrm{MS}$ 데이터를 해석하여, 각각 ginsenoside F1 (1), ginsenoside F2 (2), ginsenpside F3 (3), ginsenoside Ia (4) 및 notoginsenoside $\mathrm{Fe}$ (5)로 구조 동정 하였다. 화합물 2-5는 인삼열매에서는 이번에 처음 분리 보고되었다. 분리한 5 종의 화합물을 인체 암세포주 (HCT-116, SK-OV-3, HeLa, HepG2, SK-MEL-5)에 처리하여 세포독성을 측정하였다. 이 중 화합물 2,4 , 및 5 가 인체 암세 포주에 대해 세포독성을 저해시키는 것을 알 수 있었다. 화합 물 2는 SK-MEL-5, HepG2, HeLa세포에서 $\mathrm{IC}_{50}$ 값이 82.8, $86.8,78.3 \mu \mathrm{M}$ 로 확인되었다. 화합물 4는 HCT-116, SK-MEL5, SK-OV-3, HepG2, HeLa 세포에서 $\mathrm{IC}_{50}$ 값이 24.5, 25.4, $26.3,22.0,24.9 \mu \mathrm{M}$ 로 확인되었다. 화합물 5는 SK-MEL-5 세 포에서 $\mathrm{IC}_{50}$ 값이 $81.7 \mu \mathrm{M}$ 로 확인되었다. 인삼 열매에서 분리 한 화합물 $\mathbf{2}, \mathbf{4}$, 및 $\mathbf{5}$ 가 암세포주에 대해 강한 세포독성을 나타 내는 것을 확인하였으며, 이 화합물들은 공통적으로 3 번 수산 기에 glucopyranose를 가지고 있음을 확인하였다.

Keywords 암세포독성 - 인삼 - 인삼열매 - 인체암세포주 · Ginsenoside

감사의 글 본 논문은 농림축산식품부 수출전략기술개발사업(과제번호: 31402603-2-HD020)의 지원에 의해 이루어진 것입니다. 지원에 감사드립니다.

\section{References}

1. Gillis CN (1997) Panax ginseng pharmacology: a nitric oxide link. Biochem Pharmacol 54: 1-4

2. Li CP, Li RC (1973) An introductory note to ginseng. Am J Chin Med 1: 249-261

3. Singh VK, Agarwal SS, Gupta BM (1984) Immunomodulatory activity of Panax ginseng extract. Planta Med 50(6): 462-465

4. Choi KT (2008) Botanical characteristics, pharmacological effects and medicinal components of Korean Panax ginseng C A Meyer. Acta Pharmacol Sin 29(9): 1109-1118

5. Kim YS, Kang KS, Kim SI (1990) Study on antitumor and immunomodulating activities of polysaccharide fractions from Panax ginseng: comparison of effects of neutral and acidic polysaccharide fraction. Arch Pharm Res 13(4): 330-337

6. Kim MH, Byon YY, Ko EJ, Song JY, Yun YN, Shin TK, Joo HG (2009) Immunomodulatory activity of ginsan, a Polysaccharide of Panax ginseng, on dendritic cells. Korean J Physiol Pha 13: 169-173

7. Lee DY, Kim HG, Lee YG, Kim JH, Lee JW, Choi BR, Jang IB, Kim GS, Baek NI (2018) Isolation and quantification of ginsenoside Rh23, a new anti-melanogenic compound from the leaves of Panax ginseng. Molecules 23(2): 267-278

8. Wang CZ, Wu JA, Mcentee E, Yuan CS (2006) Saponins composition in American ginseng leaf and berry assayed by high-performance liquid chromatography. J Agric Food Chem 54(6): 2261-2266

9. Yahara S, Tanaka O, Komori T (1976) Saponins of the leaves of Panax ginseng C. A. Meyer. Chem Pharm Bull 24: 2204-2208

10. Chae SW, Kang KA, Chang WY, Kim MJ, Lee SJ, Lee YS, Kim HS, Kim DH, Hyun JW (2009) Effect of compound K, a metabolite of ginseng saponin, combined with ã-ray radiation in human lung cancer cells in vitro and in vivo. J Agric Food Chem 57: 5777-5782

11. Mai TT, Moon JY, Song YW, Viet PQ, Phuc PV, Lee JM, Yi TH, Cho MJ, Cho SK (2012) Ginsenoside F2 induces apoptosis accompanied by protective autophagy in breast cancer stem cells. Cancer Lett 321(1): 144-153

12. Skehan P, Storeng R, Scudiero D, Monks A, McMahan J, Warren TJ, Bokesch H, Kenny S, Boyd MR (1990) New colorimetic cytotoxicity assay for anticancer-drug screening. J Natl Cancer Inst 82(13): 11071112

13. Shen R, Laval S, Cao X, Yu B (2018) Synthesis of $\ddot{A}^{20}$-ginsenosides $\mathrm{Rh}_{4}$, (20E) $-\mathrm{Rh}_{3}, \mathrm{Rg}_{6}$, and $\mathrm{R} k_{1}$ : a general approach to access dehydrated ginsenosides. J Org Chem 83(5): 2601-2610

14. Wu W, Qin Q, Guo Y, Sun J, Liu S (2012) Studies on the chemical transformation of 20(S)-protopanaxatriol (PPT)-type ginsenosides $\mathrm{R}_{\mathrm{e}}$, $\mathrm{R}_{\mathrm{g} 2}$, and $\mathrm{R}_{\mathrm{f}}$ using rapid resolution liquid chromatography coupled with quadruple-time-of-flight mass spectrometry (RRLC-Q-TOF-MS). J Agr Food Chem 60(40): 10007-10014

15. Peng M, Yi YX, Zhang D, Ding Y, Le J (2018) Stereoisomers of saponins in Panax notoginseng(Sanqi):a review front. Pharmacol 9(188): $1-18$

16. Su L, Mo JG, Wei YL,Chen QH, Pan YK (2012) Chemical constituents of saponins from leaves of Camellia euphlebia. Zhongcaoyao 43(5): 877-879

17. Yang MC, Seo DS, Hong JK, Hong SH, Kim YC, Lee KR (2008) Ginsenosides from the roots of Korean cultivated-sild ginseng. Nat Prod Sci 14(3): 171-176

18. Seo S, Tomita Y, Tori K, Yoshimura Y (1977) Determination of the absolute configuration of a secondary hydroxy group in a chiral secondary alcohol using glycosidation shifts in carbon-13 nuclear magnetic resonance spectroscopy. J Am Chem Soc 100(11): 3331-3339

19. Li KK, Xu F, Gong XJ (2016) Isolation, purification and quantification of ginsenoside F5 and F3 isomeric compounds from crude extracts of flower buds of Panax ginseng. Molecules 21(3): 315/1-315/12

20. Dou D, Wen Y, Pei Y, Yao X, Chen Y, Kawai H, Fukushima H Ginsenoside-Ia: a novel minor saponin from the leaves of Panax ginseng. Planta Med 62(2): 179-181

21. Wang HP, Yang XB, Yang XW, Liu JX, Wang YP, Zhang LX (2013) Chemical constituents from roots and rhizomes of Panax ginseng cultivated in Jilin province. Zhongguo Zhongyao Zazhi 38(17): 28072817 